\title{
THE CONSCIOUS LEADER IN THE DIGITAL VORTEX ERA
}

\author{
Marius Calin Benea ${ }^{308}$
}

https://doi.org/10.31410/itema.2018.884

\begin{abstract}
Why does humanity need conscious leaders? Because our world is changing faster than we can adapt. Being caught in a speed trap, complexity and uncertainty, many of us are not ready for this acceleration. The conscious leader is a precious resource not only in the digital age of transformations of all kinds, but in all the ages in which an enlightened mind is needed. Companies need conscious leaders because they are responsible and well informed, they are authentic and act with intent, daring and courage. More than ever, consciousness is their antidote against the disturbing factors that generate the great changes. Even more, in full „, digital whirlwind”, the conscious leader will direct the master orchestra of transformations. This article will answer the question: , when and under what conditions is a company ready to become a virtuoso of digital transformation?"
\end{abstract}

Keywords: consciousness, leader, digital.

\section{INTRODUCTION}

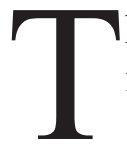

he phrase "Vortex Digital" describes the force that digital transformation exerts on all institutions and how companies are attracted by the core of this phenomenon.

Today, companies need conscious leaders. In addition to the fact that leaders need to stimulate constant transformation, they must understand and value the diversity, inclusion, talent management, and ethics - fundamental aspects of conscious man's mentality.

Intelligence is no longer sufficient. Intelligence brings you to the forefront, but to stay there you must be fully aware. This is all the more true today, when the need for transformation is stringent and constant.

\section{CONSCIOUSNESS IS NEW (FORMAT) INTELLIGENCE}

Consciousness helps us think deeper, to learn faster, to work better.

To act consciously, we must examine ourselves to truly know ourselves, to think ample to see the multitude of possibilities, to be realistic in order to be more authentic and to act in the life and leadership, and to raise the bar for it worked to our true potential.

Our world is changing faster than we can adapt. Caught like in a speed trap, complexity and uncertainty, many of us are not ready for this acceleration. Faced with the challenges, we operate on the automatic pilot. We are too troublesome and lose opportunities. We are hijacked by conflicting values of polarizing relationships. In uncertainty we react with fear and

308 „Politehnica” University Timişoara, Faculty of Engineering Hunedoara, str. Revoluției, Nr.5, Hunedoara, Romania 
mistrust. Stress and burnout predominate because most of us do not perform at their true potential.

Organizations do not adapt better. More than half of the attempts to produce change fail. Markets are changing faster than organizations succeed in reinventing themselves. The gap between the leaders we have and the leaders we need is getting bigger. The ability of directors to be leaders of change is set under the sign of doubt. So, many organizations are dominated by slow execution, of underdevelopment, by an unhealthy and underperforming culture.

Human solidarity is extremely fragile. Cynicism and mistrust prevents us from solving the most complex problems of society. The broken families, racial tensions, trade wars, climate change they only exacerbate the situation. And all this is happening in times when it is more than ever necessary for people to unite to solve highly pressing issues - such as human rights, discrimination, poverty, protecting and preserving the environment. [1]

\section{THE CONSCIOUS LEADERSHIP}

If the concept of mindfulness can be looked down upon by some people, considering it as a blue or utopian flower, more and more business managers incorporate this practice into their daily lives and aspire to become conscious leaders.

The conscious leader is defined by his ability to develop his presence and attention on a daily basis. He is present in what he does; he is attentive to himself, to others and to his environment. Rather than being anchored in unhealthy defense mechanisms in the face of adversity, he seeks clarity by giving himself space to take an introspective and benevolent look at himself and his performance.

The work of Janice Marturano, author of Finding a Space to Lead [2], is often cited as a pioneer in conscious leadership. Reading his book, we understand that the conscious leader will be better able to adapt to a complex environment, where agility and emotional intelligence are essential skills to cope with the technological evolution that leads us to the world. 4.0.

\section{The conscious leader reassures while being realistic in times of change}

A popular saying is that when we are depressed, we live in the past and when we are anxious, we are planning too much in the future. Mindfulness will help leaders focus on the present moment, on the task or goal they are achieving at the moment.

\section{The conscious leader is kind to himself and to others}

This aspect reminds leaders to take care of themselves and be caring towards their person. People who rank high in a company's hierarchy often tend to be very demanding of themselves. By adopting this way of thinking, this leads them to be just as demanding of those around them and their work teams, which can complicate relationships. Developing empathy and openness opens the door to a more harmonious working relationship, which in turn increases the company's performance.

The conscious leader engages the commitment and the deployment of the talents of his collaborators

Moving into a positive environment, based on core values such as respect and listening to oneself and others, will increase the manager's ability to develop compassion. This quality is essential to strengthen the bond of trust towards its employees. 


\section{The conscious leader innovates more to find solutions to complex issues}

By having the mind absorbed by the worries of everyday life, the leader who does not practice mindfulness may tend to go around in circles.

However, gradually exercising his conscious leadership, he will see more clearly. The expression to think outside the box will make sense here, because it will be in the right frame of mind to go into solution mode instead of indulging in the status quo.

\section{How to develop a more conscious leadership?}

Still according to Janice Marturano, conscious leadership is developing by offering moments of hindsight during which it is essential to tame the tranquility and silence to be able to empty and take a healthy distance with our environment. So, the manager will be able to bounce back faster and find innovative solutions to the issues and challenges he faces.

\section{To devote to his tasks in a conscious way}

Being fully attentive at times when we normally perform our tasks mechanically allows us to focus on the present moment. For example, the conscious leader might choose to dwell on the sensation of the cold liquid that hydrates his mouth by drinking a glass of water. It only takes a few minutes, but focusing on these innocent little acts in a conscious way allows you to step back and refocus.

\section{Give yourself a moment of introspection}

With the hectic pace of today's life, everyone can feel that he does not have a minute to himself. It's easy to fall into the trap of the autopilot where the days go by without one having stopped to reflect on one's deep aspirations, one's well-being, on reaching one's goals. Looking at one's inner world allows one to answer questions that may seem unanswered, as long as one does not take the time to dwell on them.

\section{Align what we do with who we are}

The conscious leader is also an authentic leader in the sense that he is faithful to himself. $\mathrm{He}$ deploys energy in his personal growth and he's trying to find out who he is and what passionate him in order to take advantage of its full potential.

\section{Stop believing in his invincibility}

It is healthy and even important to try to surpass oneself and become the best version of oneself. However, when the desire for performance begins to encroach on the physical and mental health of the leader, we understand that it is time to stop. The leader must understand that he is not immune to burnout and that the balance between work and personal life must be well balanced.

\section{The practice of meditation}

Meditation can take many forms. The manager can choose to incorporate 10 to 15 minutes of traditional meditation every morning into his routine, silently or accompanied by a guided meditation. Or, he may decide to incorporate breaks into his work routine and schedule moments to consciously breathe and take a step back on the tensions and emotions accumulated during his day. Its performance and productivity will only get better.

In a world where instantaneity is foreground, the perseverance that development requires and the practice of conscious leadership may seem like too much investment in time and energy, because the results are sometimes difficult to discern on the short term. 
Remember during your journey to the conscious leadership that more and more scientific research is demonstrating the physical, emotional and intellectual benefits of mindfulness. This is particularly true in a world where taking a step back from oneself, others, and events has become essential to ensuring our sustainability as a leader despite the fact that sometimes taking a few moments back to act as a conscious leader may seem like to be is worthy of a revolutionary act.

\section{CONCLUSIONS}

Conscious leaders come into play with their best version, challenging others to do the same. Leadership is not a function, leadership can be anyone. By becoming more aware, they will find the sense of work and will be more effective in inspiring others to follow.

People want to be inspired and are open to being led. The leader who understands where his people are, who perceives their receptivity to change and their interest in advancing the team and the progress of the organization will be successful in what they do. It is vital to understand that not all people are resistant to change.

The solutions to many of our problems lie in ourselves, and among them is the solution to managing the change and the disturbing factors we face. Our inner strength and wisdom are the best solution to manage transformations.

In an overactive market, leaders must be over-aware of what is happening and what they can do in the current reality to thrive. Self-awareness is truly the only way to success.

\section{REFERENCES}

[1] Rosen, B., Swann, E. K., (2018) Conscious: The Power of Awareness in Business and Life, Wiley, pp. 13-21.

[2] Marturano, J., (2014) Finding the Space to Lead: A Practical Guide to Mindful Leadership, Bloomsbury Press, , pp. 208. 